\title{
Prevalence of Psychiatric Disorders Among Unaccompanied Asylum- Seeking Adolescents in Norway
}

\author{
Marianne Jakobsen ${ }^{1, *}$, Melinda A. M. Demott ${ }^{1}$ and Trond Heir ${ }^{1,2}$ \\ ${ }^{I}$ Norwegian Centre for Violence and Traumatic Stress Studies, Postboks 181 Nydalen Oslo, Norway; ${ }^{2}$ University of \\ Oslo, Institute of Clinical Medicine, Oslo, Norway
}

\begin{abstract}
Unaccompanied asylum-seeking children (UASC) are known to be subjected to several potentially traumatic life events, risking more mental health problems than other populations of same age. In this study, we aimed to explore the prevalence of psychiatric morbidity at an early stage after arrival to the host country. We performed structured clinical interviews (CIDI) with 160 male UASC from different countries (Afghanistan, Somalia, Iran), after four months in Norway. Most of the participants had experienced life threatening events (82\%), physical abuse (78\%), or loss of a close relative $(78 \%)$ in their former life. Altogether $41.9 \%$ of the participants fulfilled diagnostic criteria for a current psychiatric disorder. The most prevalent diagnosis was PTSD (30,6\%), followed by MDD (9, 4\%), Agoraphobia (4, 4\%) and GAD $(3,8 \%)$. Implications of this vulnerability call for more mental health resources in the early stages of the asylum process. Increased awareness of psychiatric morbidity in UASC may improve the prognosis, give more appropriate care, and ease the integration process on all levels of society.
\end{abstract}

Keywords: Afghan, asylum, mental health, PTSD, refugee children, Somali.

\section{INTRODUCTION}

The number of unaccompanied asylum-seeking children (UASC) arriving in Norway the last ten years has varied between 322 (in 2005) and 2500 (in 2009) [1]. Also, the nationalities represented have differed from year to year. European countries received 13.300 asylum claims from UASC in 2011 , which is $75 \%$ of the worldwide number [2]. Refugee adolescents are known to encounter numerous risk factors that can cause psychological distress, including exposure to violence, and multiple losses [3-5].

Several studies have examined the rates of psychological distress in different samples of refugee children, using selfreport instruments, or instruments filled in by parents, teachers or others [6-10]. A large study from Belgium and the Netherlands has revealed higher levels of PTSD symptoms for UASC in comparison to the host populations, and also compared to refugee minors that migrate together with their caregivers [11]. UASC in the same study also reported higher levels of exposure to physical and sexual maltreatment and higher levels of anxiety and depression.

Most studies in this field have used estimates of diagnostic "caseness" based on selfreport instruments filled in by parents, teachers, or the youth themselves; either with "pen and pencil" or with the aid of translators [12]. How to deal with the challenge of whether or not to include illiterate subjects, are usually not discussed in detail. Also, the possible impact of different modes of testing in the same research project; i.e. reading and writing by yourself versus having

*Address correspondence to this author at the Norwegian Centre for Violence and Traumatic Stress Studies Postboks 181 Nydalen Oslo, Norway; Tel: +47225955 00 / +4748 0239 28; Fax: +47 225955 01;

E-mail: marianne.jakobsen@nkvts.unirand.no another person read and write for you, is very seldom discussed [13]. Even a renowned analysis of validity problems in the field of transcultural epidemiology does not address this challenge [14].

Other studies have focused on the cross-cultural validity and context relevance of existing screening instruments, seeking adaptation to new settings, while keeping the internal consistency and the construct validity of the scales [15]. Diagnostic evaluations or validation of the appropriate "cutoff" values are often lacking [16].

There are few prevalence studies focusing on young refugees or UASC and to our knowledge none that have used clinical evaluations or diagnostic interviews shortly after migration. On the other hand there is some research with adults, indicating that post-migrational stressors contribute significantly to the psychopathology of refugees [17]. The precise impact of post-migrational stressors can be difficult to determine due to lack of baseline measures or early diagnosis. In addition, this lack of knowledge gives immigration authorities less possibilities to plan for appropriate care when the young refugees arrive. The prevalence of psychiatric morbidity in UASC boys, within four to five months after their arrival in Norway, will be the focus of this study, in addition to self-report screens and demographic data.

\section{MATERIALS AND METHODOLOGY}

\section{Participants}

The population in this study were male, unaccompanied asylum-seeking children (UASC) arriving in Norway. Shortly after arrival, all UASC between ages 15 to 18 , were placed for 3-6 weeks in one transit centre, right outside of Oslo. At the transit centre, a research assistant kept track of 
all new arrivals. Each time our testing capacity allowed us to include some new participants she was instructed to invite the ones who had arrived most recently. Inclusion was restricted to the six largest language groups due to translation costs; Arabic, Dari, Farsi, Pashto, Somali, and Sorani. Because of changes in migration patterns, we ended up with a population consisting mostly of young men from Afghanistan and Somalia. Inclusion was done in 2009 (12 weeks), 2010 (8 weeks), and 2011 (21 weeks).

According to the statistics unit at the Norwegian Directorate of Immigration, 406 male UASCs from the actual language groups arrived in Norway during the inclusion periods. Altogether, 216 UASC were asked to participate, and were given oral information with the aid of a translator. The information stressed the fact that the research had no link to the asylum process. Out of these, 204 UASC decided to participate, and signed the informed consent form (94\% response rate). We made only one attempt to contact each individual, without offering any payment. The 204 UASC, who wanted to be in the study, all completed screening instruments at the first testing point, and no later than 3 weeks after arrival in Norway. Of these individuals, 160 completed a second assessment with a Composite International Diagnostic Interview (CIDI) [18] performed by trained clinicians 4-5 months after the first screening, in addition to a second screening for psychiatric symptoms. At the time of the second assessment, the UASC had been moved from transit and placed in asylum centres for young people or adults.

The Regional Medical Ethics Committee, South-East Norway gave this study their written approval.

All participants gave their informed consent.

\section{Measures}

Demographic information included country of origin, number of years in school, age, and whether or not their parents were alive. These data were obtained by semistructured interviews performed with the aid of interpreters. Screening instruments included Hopkins Symptom Checklist-25 (HSCL-25) [19], Harvard Trauma Questionnaire (HTQ) Part IV [20], and Stressful Life Events checklist [21]. Most translations were obtained from the Centrum 45 internet pages, and some from a previous research project by our centre [16]. The Pashto versions had to be translated and backtranslated specifically for this project. Spelling control, including some language adjustments were made with the aid of native speaking interpreters for all languages.

The participants filled in the instruments by themselves, using their native languages, on laptops with touch-screen. All three screening instruments were combined into a single questionnaire using a computer program called Multilingual Computer Assisted Self Interview (MultiCASI) [22]. Items of the questionnaire appeared one after the other on the laptop, with answering alternatives as well. A native speaker in each language had already made soundfiles for the written text. The sound of the questionnaire could be repeated until the meaning was understood by the participant. This gave all informants, regardless of reading abilities, the possibility of answering the questions without the aid of an interpreter.
The HSCL-25 questionnaire is often used as a measure of emotional distress, and is one of the several HSCL versions that have been used all over the world [12]. It has been used and validated as a self-report screening in both community settings and clinical samples [19, 23]. The HSCL-37A version is built on the HSCL-25. Several refugee studies with minors have used this questionnaire [24-26]. The HSCL-25 asks for 25 symptoms that are considered typical for depression and anxiety during the last week. Each symptom was assessed on a likert scale ranging from 1 (not at all) to 4 (extremely). In clinical refugee samples, the screen is a reliable tool for diagnosing these categories. Other research has demonstrated limited diagnostic validity for the HSCL-25 in non-clinical samples $[23,16]$.

The Harvard Trauma Questionnaire [20] was developed to assess potentially traumatic experiences, and a rich variety of post-traumatic symptoms in different cultural settings. It was developed and first used with a group of severely traumatized patients, but have also been used in larger community samples, and with asylum seeking adolescents [9].

The HTQ has four parts that can be used separately. The first three parts give descriptions of potentially traumatic events (Part I: different events that are considered potentially traumatic, and often encountered by refugees; Part II: identification of the most difficult traumatic event; Part III: physical trauma directed at the head). Part IV is a list of 30 items, where the first 16 focus on PTSD symptoms that can be used to diagnose this disorder in the DSM -IV [27]. In this paper, we use these 16 items together with the HSCL-25, in order to enable comparison of the participants who completed the diagnostic interviews with the non-participants, as well as comparison of symptom levels at the different testing points.

Stressful Life Events checklist (SLE) was developed by Tammy Bean and colleagues [21] in order to assess if an adolescent meet the criteria A1 (experienced a traumatic event) in the DSM-IV, for a diagnosis of PTSD. The twelve item checklist is used to indicate types of traumatic events to which they may have been exposed. The instrument is scored by answering yes or no on each item, and has been used in several studies with children and youth [11].

The Composite International Diagnostic Instrument (CIDI) was developed by the World Health Organization, a collaboration with the US Mental Health Administration Task Force that started in 1979 . Good validity and reliability of this structured diagnostic interview has already been reported [18]. In this study, the modules for depression, anxiety, and PTSD was presented to each informant in the same sequence. The health professionals had received certification in the use of CIDI, and performed the diagnostic interview with the aid of interpreter, either in person or on telephone, during the whole interview. In cases of doubt, the professionals discussed the individual cases until consensus were reached.

\section{RESULTS}

\section{Characteristics}

The 160 youth that completed the diagnostic psychiatric interview (CIDI) had similar age, background and psychological distress level compared with the youth who did not 
participate. No significant differences in registered characteristics of participants and non-participants were found (Table 1). Participants' selfreported age were in average 2.3 yrs $(95 \% \mathrm{CI}=1.9-2.6)$ lower than age assessed by health care professionals using radiographs of skeleton and teeth at a later stage $(p<0.001)$. These age tests were used by the immigration authorities to estimate an official chronological age for the young asylumseekers. The result was an increase from $5(3 \%)$ to $99(62 \%)$ regarding the number of participants considered to be more than 18 years old. The ages of the non-participants were in a similar range.

A slight majority reported that they were able to read and write in their own language. Less than half of the participants reported education of 5 years or more.

\section{Life events}

Table 2 show self-reported, stressful life events. Most of the participants $(96.3 \%)$ had experienced at least one of the stressful life events listed. The most frequently reported experiences were life threatening events, physical abuse, and loss of a close relative. The average number of different experiences from the scale were $6.2(\mathrm{SD}=2.2)$. Almost half of the young men had war related experiences. Loss of father was the most frequent bereavement, and a considerable part had lost both their parents (Table 1).

Table 1. Characteristics of participating and nonparticipating male unaccompanied refugee minors at arrival in Norway. Figures are given as number (\%) when others not specified.

\begin{tabular}{|l|c|c|}
\hline & $\begin{array}{c}\text { Participants } \\
\mathbf{N}=\mathbf{1 6 0}\end{array}$ & $\begin{array}{c}\text { Non-participants } \\
\mathbf{N}=\mathbf{4 4}\end{array}$ \\
\hline \hline Age, self reported & & \\
\hline Mean years (SD) & $16.23(0.83)$ & $16.09(0.77)$ \\
\hline Range & $14-20$ & $15-17$ \\
\hline Age, assessed by authorities & & \\
\hline Mean years (SD) & $18.48(2.28)$ & $18.32(2.95)$ \\
\hline Range & $15-28$ & $15-27$ \\
\hline Nationality & & \\
\hline Afghan & $122(76.3)$ & $34(77.3)$ \\
\hline Somalian & $35(21.9)$ & $9(20.5)$ \\
\hline Iran & $3(1.9)$ & $1(2.3)$ \\
\hline Literacy, selfreported & $60(37.8)$ & $12(27.3)$ \\
\hline Years of education $\geq 5$ & $73(45.8)$ & $15(34.1)$ \\
\hline Loss of parent & & \\
\hline Father & $104(65.0)$ & $27(61.4)$ \\
\hline Mother & $38(23.8)$ & $9(20.5)$ \\
\hline Both & $35(21.9)$ & $8(18.2)$ \\
\hline HCL-25, mean (SD) & $1.75(0.44)$ & $1.76(0.36)$ \\
\hline PTSS-16, mean (SD) & $34.60(9.31)$ & $35.33(9.37)$ \\
\hline
\end{tabular}

Table 2. Self reported negative life events in male unaccompanied refugee minors $(\mathrm{N}=160)$ at arrival in Norway.

\begin{tabular}{|l|r|}
\hline Drastic changes in family during the last year & $94(62,3 \%)$ \\
Separated from family against will & $82(54,7 \%)$ \\
Loss of close relative & $120(77,9 \%)$ \\
Life threatening medical problem & $43(27,9 \%)$ \\
Serious accident & $33(21,9 \%)$ \\
Natural disaster & $81(53,6 \%)$ \\
War related experiences & $74(48,7 \%)$ \\
Physical abuse & $120(77,9 \%)$ \\
Witnessing violence against others & $87(57,2 \%)$ \\
Sexual abuse & $15(9,8 \%)$ \\
Life threatening events & $125(81,7 \%)$ \\
Witnessing life threat of others & $76(49,7 \%)$ \\
\hline Any negative life event & $154(96.3 \%)$ \\
\hline
\end{tabular}

\section{Selfreported Symptoms}

Measurements of general psychological distress (HSCL25) and posttraumatic stress (PTSS-16) were obtained shortly after arrival, and after four months (Table 3). There was no significant change in score during this time period.

Table 3. Self reported general psychological distress and posttraumatic stress in male unaccompanied refugee minors $(n=149)$ at two time points: at arrival and after 4 months in Norway.

\begin{tabular}{|l|c|c|c|}
\hline & At Arrival & After 4 Months & p-Value \\
\hline \hline HCL-25 & $1.75(0.37)$ & $1.77(0.37)$ & 0.66 \\
\hline PTSS-16 & $34.64(9.35)$ & $35.12(9.42)$ & 0.51 \\
\hline
\end{tabular}

\section{Psychiatric Morbidity at 4 Months}

Table 4 show psychiatric morbidity according to DSMIV [27] diagnoses. As much as $41.9 \%$ of the participants fulfilled the diagnostic criteria for a current psychiatric disorder. The most prevalent diagnosis was Posttraumatic Stress Disorder (PTSD), followed by Major Depressive Disorder (MDD), Agoraphobia and Generalized Anxiety Disorder (GAD).

\section{Worst Incident in Relation to PTSD}

The participants had to choose a "worst incident" from their trauma history, and think of this incident when asked about the related PTSD symptoms, in order to be diagnosed. The most common incidents among those 49 youth who were diagnosed with PTSD were: "a life threatening episode", given by $16(32,6 \%)$; next came "witnessing cruelty 
against others" $11(22,4 \%)$; followed by "experiences in prison" $10(20,4 \%)$.

Table 4. Psychiatric morbidity among male unaccompanied refugee minors $(n=160) 4$ months after arrival in Norway. All diagnoses according to the DSM-IV [ref].

\begin{tabular}{|l|c|}
\hline Psychiatric Disorder & $\begin{array}{c}\text { Current Prevalence } \\
\text { N (\%) }\end{array}$ \\
\hline \hline Major depressive disorder & $15(9.4)$ \\
Dysthymic disorder & $7(4.4)$ \\
Mood disorder with depressive features due to & $4(2.5)$ \\
general medical condition & \\
Panic disorder & $1(0.6)$ \\
Agoraphobia & $7(4.4)$ \\
Generalized anxiety disorder & $6(3.8)$ \\
Social anxiety disorder & $3(1.9)$ \\
Specific phobia & $5(3.1)$ \\
Post Traumatic stress Disorder & $49(30.6)$ \\
Any psychiatric disorder & $67(41.9)$ \\
\hline
\end{tabular}

\section{DISCUSSION}

This study demonstrates that unaccompanied refugee minors are a very vulnerable group with a high prevalence of psychiatric morbidity. The young men that we interviewed had experienced numerous threatening, horrible and potentially traumatic events, and the most prevalent psychiatric disorder was PTSD. A majority of the youth was bereaved, and lacked the protection and social stability that parents could have offered. In addition to PTSD, high prevalence of depressive and anxiety disorders were found.

To our knowledge, this is the first study on refugee minors that has applied clinical interviews soon after arrival to the host country. Compared to studies that have used this methodological approach in a later phase [28, 29], our findings suggests considerable higher prevalence of both depression and PTSD. Servan-Schreiber, Le Lin and Birmaher, found that $11,5 \%$ of Tibetan refugee children $(\mathrm{n}=61)$ suffered from PTSD, and the same proportion met criteria for major depression (MDD). Tousignant et al. did not measure PTSD in a group of 203 adolescent refugees from 35 countries, but diagnosed simple phobia in $21 \%$, overanxious disorder in $13 \%$ and MDD in 5\%. Plausible explanations are different diagnostic approaches as well as refugee populations with different backgrounds. Participants from our study were young men, mainly from Afghanistan and Somalia, parts of the world with a history of war and a corresponding weakening of the social fabric. Low levels of literacy, frequent exposure to loss and trauma, and limited access to health facilities underscores the impact of psychosocial adversities in their upbringing. In that respect, our findings are similar to previous studies using estimates of "caseness" according to selfreport instruments [8-11]. In general, studies on refugee minors show higher prevalence of psychopathology than studies on youth from the main population. In a comparable study with adolescents from different racial and ethnic groups in the USA, they found a prevalence of PTSD from 7,4\% (Latino) to 3,4\% (Non-Latino Black) [30].

The burden of psychosocial problems and postmigrational events for adult asylumseekers and refugees in their new host countries, are well documented [31,32]. Our finding that symptom levels of general psychological distress and posttraumatic stress were stable from arrival to the time of the diagnostic interviews, indicate that the psychiatric morbidity was present when the youth arrived, and therefore probably not an effect of the stressors connected to life as an asylum seeker per se. Psychiatric morbidity related to psychosocial problems later in the refugees lives may also be compounded by the presence of a considerable number of traumatic experiences from their former lives [9]. An illustration of this may be the experiences chosen as the "worst incident" related to the PTSD diagnoses with this research population. Life-threatening experiences dominated together with witnessing cruelty against others, and severe prison events. Many of these young men told us that their worst experience happened while they were imprisoned in transit countries, such as Lebanon, Greece and Italy.

Our study demonstrated a gap between self reported age and the official age estimates given by the immigration authorities, on the basis of x-rays and dental examinations performed after some months. This reflects a considerable uncertainty about the participant's true chronological age. Birth registration services are often nonfunctioning in the countries the UASC come from, and the scientific basis for age assessment is controversial, since the tests have their greatest uncertainty in the ages with the greatest natural variation, e.g. ages 15 to 21[33]. The uncertainty with skeletal and dental age assessment is considered to be large, i.e. between two and five years [34]. This could have crucial consequences for a large part of the young asylum seekers, since they no longer are considered minors and in need of special protection according to UNHCR [35]. The increase from 5 to 99 in the numbers of asylum seekers over 18 years in our population, due to age testing later on, may impact our claim that we have conducted a prevalence study on unaccompanied refugee minors. In that respect, our study population should be considered to be more representative for UASC according to self report, since this was the only source of age determination available on arrival.

\section{METHODOLOGICAL CONSIDERATIONS}

Strength of this study is the use of structured diagnostic interviews with trained health professionals, and unlimited use of time and interpreters. We also argue that the recruitment procedures gave a representative sample of UASC from the chosen countries.

The self-report instruments were filled in by the informants themselves, regardless of literacy, because of the MultiCASI method [22]. There was no need to exclude illiterate subjects, or treat them differently than the other informants. We believe that this improved the validity of the testing procedure. 
The life situation of the informants, together with the distance, both physically and culturally to their countries of origin, gave us limited access to objective data concerning their backgrounds. The informants themselves were the only source of information, and the clinical assessments may have been influenced by inaccurate data. The health professionals performing the CIDI interviews were all experienced clinicians, who had worked extensively with refugees, using interpreters. We argue that this has improved the validity of the diagnostic procedures.

The study sample was recruited from young asylum seekers that arrived Norway in a period of two years. UASC areas of origin vary over time and thus, our results may not be representative for populations of UASC from other parts of the world.

\section{CONCLUSION}

Unique to this study is that these high numbers of unaccompanied minor asylum seekers with a psychiatric diagnosis were found a relatively short time after the UASC arrived, and thus in the early stages of their stay in the country where they apply for asylum. As far as we know, this has not been the focus of any previous study, and contrasts earlier findings that most refugees experience a period of wellbeing and hopefulness shortly after arrival in the host country [36, 37], with lower mental health problems, and clearly illustrates the overall vulnerable situation of UASC.

The manifest presence of severe symptoms presents a challenge for the host country as it may be difficult to meet the complex needs for support UASC have in this specific phase of their lives. Therefore, expanded and multidisciplinary professional staff in the reception centres for UASC who recently arrived is needed in order to give appropriate physical and emotional support, and to create a safe living environment for all UASC [3,38]. This involves ensuring basic needs, and sufficient time to support all UASC in developing a sense of stability, safety and trust [39].

Forced migration is part of a global process where populations from different corners of the world interact because of war and natural catastrophes. Increased trade, mass media, the internet, and improved communications are also factors related to the movement of people [40]. These developments affect public health in the host countries, and pose a challenge to the systems responsible for treatment and follow up of psychiatric health problems.

We believe that the prognosis may be better if traumatized children are threated in an early phase. This would also ease the integration process on all levels of society.

\section{CONFLICT OF INTEREST}

The authors confirm that this article content has no conflict of interest.

\section{ACKNOWLEDGEMENTS}

This study was partially funded by the Norwegian directorate of Immigration.

Special gratitude to Liv Berit Løken for her care and assistance with all aspects of the data collection, Lars Erik
Eide Johansen for his assistance with the diagnostic interviews, to our very skilled interpreters, and to all the young participants.

\section{REFERENCES}

[1] Norwegian Directorate of Immigration, UDI (2011): http://www.udi.no/oversiktsider/Statistikk-og-analyse/Statistikk/ Asyl/Enslige-mindrearige-asylsokere/

[2] UNHCR (2012) Global trends 2011. United Nations High Commissioner for Refugees, Geneva.

[3] Fazel M, Reed R V, Panter-Brick C, Stein A. Mental health of displaced and refugee children resettled in high-income countries: risk and protective factors. Lancet 2012; 379: 266-82.

[4] Huemer J, Karnik NS, Voelkl-Kernstock S, et al. Mental health issues in unaccompanied refugee minors. Child Adolesc Psychiatry Ment Health 2009; 3: 13.

[5] Bronstein I, Montgomery P. Psychological distress in refugee children: a systematic review. Clin Child Fam Psychol 2011; 14 44-56.

[6] Sourander A. Behavior problems and traumatic events of unaccompanied refugee minors. Child Abuse Negl 1998; 22: 719-27.

[7] Heptinstall E, Sethna V, Taylor E. PTSD and depression in refugee children: associations with pre-migration trauma and postmigration stress. Eur Child Adolesc Psychiatry 2004; 13: 373-80.

[8] Derluyn I, Broekaert E, Schuyten G, De Temmerman E. Posttraumatic stress in former Ugandan child soldiers. Lancet 2004; 363: 861-63.

[9] Hodes M, Jagdev D, Chandra N, Cunniff A. Risk and resilience for psychological distress amongst unaccompanied asylum seeking adolescents. J Child Psychol Psychiatry 2008; 49: 723-32.

[10] Bronstein I, Montgomery P, Dobrowolski S. PTSD in asylumseeking male adolescents from Afghanistan. J Trauma Stress 2012; 25: 551-7.

[11] Bean T, Derluyn I, Eurelings-Bontekoe E, Broekaert E, Spinhoven P. Comparing psychological distress, traumatic stress reactions, and experiences of unaccompanied refugee minors with experiences of adolescents accompanied by parents. J Nerv Ment Dis 2007; 195: 288-97.

[12] Hollifield M, Warner TD, Lian N. Measuring trauma and health status in refugees: A critical review. JAMA 2002; 288: 611-21.

[13] Moum T. Mode of administration and interviewer effects in selfreported symptoms of anxiety and depression. Soc Indicator Res 1998; 45: 279-318.

[14] Van Ommeren M. Validity issues in transcultural epidemiology. $\mathrm{Br}$ J Psychiatry 2003; 182: 376-8.

[15] Mels C, Derluyn I, Broekaert E. Community-based cross-cultural adaptation of mental health measures in emergency settings: validating the IES-R and HSCL-37A in Eastern democratic Republic of Congo. Soc Psychiatr Epidemiol 2010; 45: 899-910.

[16] Jakobsen M, Johansen L E, Thoresen S. The validity of screening for post-traumatic stress disorder and other mental health problems among asylum seekers from different countries. J Refugee studies 2011; 24: 171-86.

[17] Silove DM, S. I., Field A, Manicavasagar V, Steel Z. Anxiety, depression and PTSD in asylum seekers: associations with premigration trauma and post-migration stressors. Br $\mathrm{J}$ Psychiatry 1997; 170: 351-7.

[18] Wittchen HU, Robins LN, Cottler LB, Sartorius N, Burke JD, Regier D. Cross-cultural feasibility, reliability and sources of variance of the Composite International Diagnostic Interview (CIDI). Br J Psychiatry 1991; 159: 645-53.

[19] Mollica R F, Wyshak G, de Marneffe D, Tu B, Yang T, Khuon F. Hopkins Symptom Checklist 25 (HSCL-25): manual cambodian, laotian and vietnamese versions. Torture 1996; (Suppl 1): 35-42.

[20] Mollica R F, Caspi-Yavin Y, Bollini P, Truong T, Tor S, Lavelle J. The Harvard Trauma Questionnaire: validating a cross-cultural instrument for measuring torture, trauma, and posttraumatic stress disorder in Indochinese refugees. J Nerv Ment Dis 1992; 180: 1116.

[21] Bean T, Eurelings-Bontekoe E, Derluyn I, Spinhoven P. Stressful life events (SLE): User's Manual 2004; Centrum'45, Oegstgeest. 
[22] Knaevelsrud C, Müller J. MultiCASI (Multilingual Computer Assisted Self Interview). CD-ROM, CDSP: ISBN: 978-3-540-717805. Berlin: Springer 2008.

[23] Sandanger I, Moum T, Ingebrigtsen G, Dalgard OS, Sorensen T, Bruusgaard D. Concordance between symptom screening and diagnostic procedure: the Hopkins Symptom Checklist-25 and the Composite International diagnostic interview I. Soc Psychiatry Psychiatr Epidemiol 1998; 33: 345-54.

[24] Bean T, Derluyn I, Eurelings-Bontekoe E, Broekaert E, Spinhoven P. Validation of the multiple language versions of the Hopkins Symptom Checklist-37 for refugee adolescents. Adolescence 2007; 42: 51-71

[25] Bronstein I, Montgomery P, Ott E. Emotional and behavioural problems amongst Afghan unaccompanied asylum-seeking children: results from a large-scale cross-sectional study. Eur Child Adolesc Psychiatry 2013; 22(5): 285-94.

[26] Bean T, Eurelings-Bontekoe E, Derluyn I, Spinhoven P. Hopkins Symptom Checklist-37 for Adolescents (Hscl-37a): User's Manual 2004; Centrum'45, Oegstgeest.

[27] American Psychiatric Association. Diagnostic and Statistical Manual of Mental Disorders, $4^{\text {th }}$ edition. Washington, DC: 1994.

[28] Servan-Schreiber D, Le Lin B, Birmaher B. Prevalence of posttraumatic stress disorder and major depressive disorder in Tibetan refugee children. J Am Acad Child Adolesc Psychiatry 1998; 37: 874-9.

[29] Tousignant M, Habimana E, Biron C, Malo C, Sidoli-Le Blanc E, Bendris N. The Quebec adolescent refugee project: psychopatology and family variables in a sample from 35 nations. J Am Acad Child Adolesc Psychiatry 1999; 38: 1426-32.

[30] Green JG, Gruber MJ, Kessler RC, et al. Diagnostic validity across racial and ethnic groups in the assessment of adolescent DSM-IV disorders. Int J Methods Psychiatr Res 2012; 21(4): 311-20.
[31] Carswell K, Blackburn P, Barker C. The relationship between trauma, postmigration problems and the psychological well-being of refugees and asylum seekers. Int. J Soc psychiatry 2011; 57(2): 107-19.

[32] Silove DM, Sinnerbrink I, Field A, Manicavasagar V, Steel Z. Anxiety,depression and PTSD in asylum seekers: associations with pre-migration trauma and post-migration stressors. Br J Psychiatry 1997; 170, 351-7.

[33] Hjern A, Brendler-Lindqvist M, Norredam M. Age assessment of young asylum seekers. Acta paediatrica 2012; 101: 4-7.

[34] Crawley H. When is a child not a child. Immigration Law Practitioners Association: London 2007.

[35] CRC Convention on the rights of the child; 1990. Adopted and opened for signature, ratification and accession by General Assembly resolution $44 / 25$ of 20 November 1989. Entry into force 2 september 1990, in accordance with article 49.

[36] Beiser M. Changing Time Perspective and Mental Health among Southeast-Asian Refugees. Cult Med Psychiatry 1987; 11: 437-64.

[37] Sachs E, Rosenfeld B, Lhewa D, Rasmussen A, Keller A. Entering exile: Trauma, mental health, and coping among Tibetan refugees arriving in Dharamsala, India. J Trauma Stress 2008; 21: 199-208.

[38] Reijneveld SA, de Boer JB, Bean T, Korfker DG. Unaccompanied adolescents seeking asylum: poorer mental health under a restrictive reception. J Nerv Ment Dis 2005; 193: 759-61.

[39] Watters C, Ingleby D Locations of care: meeting the mental health and social care needs of refugees in Europe. Int J Law Psychiatry 2004; 27: 549-70.

[40] Boland K Children on the move: a report on children of Afghan origin moving to western countries. UNICEF: Geneva 2010.

Received: October 03, 2013

Revised: February, 17, 2014

Accepted: March 20,2014

(C) Jakobsen et al.; Licensee Bentham Open.

This is an open access article licensed under the terms of the Creative Commons Attribution Non-Commercial License (http://creativecommons.org/licenses/by-nc/3.0/) which permits unrestricted, non-commercial use, distribution and reproduction in any medium, provided the work is properly cited. 